\title{
Acute bacterial meningitis in adults
}

\author{
Yasbanoo Moayedi MD, Wayne L. Gold MD
}

Bacterial meningitis is a medical emergency, and timely antibiotic therapy is critical

A recent retrospective study including 125 adults with proven bacterial meningitis reported a $30 \%$ increase in unfavourable outcomes (defined as death or neurologic deficits resulting in an inability to return to work or school) for every hour that antimicrobial therapy was delayed. ${ }^{1}$ If lumbar puncture is expected to be delayed, even for neuroimaging, antibiotics should be promptly administered. ${ }^{2}$

Analysis of cerebrospinal fluid can be used to support the diagnosis of bacterial meningitis when Gram staining and culture are negative because of prior antimicrobial administration

The following findings on analysis of cerebrospinal fluid (CSF) predict a bacterial rather than a viral cause of meningitis with at least $99 \%$ certainty: a leukocyte count of at least $2000 \times$ $10^{6} / \mathrm{L}$, a CSF glucose level of less than $1.9 \mathrm{mmol} / \mathrm{L}$ and a CSF:blood glucose ratio of less than 0.23 . These findings have been retrospectively validated in only one study involving adults with acute meningitis and therefore should not be used alone to decide on the initiation of antimicrobial therapy in an individual patient. Up to $10 \%$ of patients with culture-proven bacterial meningitis will have nondiagnostic CSF profiles. ${ }^{2,3}$

\section{Select patients may safely undergo lumbar puncture without prior com- puted tomography of the brain}

Prospective analysis of 301 adults who had clinically suspected meningitis found that those most likely to have abnormal computed tomography (CT) scans were 60 years or older, were immunocompromised, had a prior history of neurologic disease or had new-onset seizure, papilledema, focal neurologic deficits or abnormalities on neurologic examination, including altered level of consciousness. $^{2}$ The absence of these findings had a $97 \%$ negative predictive value for identifying patients with normal CT scans of the brain. In patients without any of these findings, the Infectious Diseases Society of America recommends proceeding to immediate lumbar puncture without prior CT, provided there are no other contraindications. ${ }^{2}$

\section{Clinical outcomes may be improved with adjuvant corticosteroid therapy}

A randomized placebo-controlled trial involving 301 adults with suspected bacterial meningitis showed a reduction in the combined outcome of death and neurologic morbidity from $25 \%$ to $15 \%$ with the use of dexamethasone when the first dose was given before, or at least concomitant with, the first dose of antibiotics. ${ }^{4}$ In 2004, the Infectious Diseases Society of America recommended this course of treatment in adults with suspected or proven pneumococcal meningitis. ${ }^{2}$ Subsequent studies have shown conflicting results, but a large meta-analysis of 24 studies involving 4041 participants in industrialized nations suggested a reduction in hearing loss and short-term neurologic sequelae with corticosteroid use in those with bacterial meningitis from any cause, without a reduction in mortality. ${ }^{5}$
CMAJ invites submissions to "Five things to know about ..." Submit manuscripts online at http://mc.manuscriptcentral.com/cmaj
The choice of empirical antimicrobial therapy for bacterial meningitis must take the patient's age and immune status into account

Current guidelines for empirical therapy appear in Appendix 1 (available at www.cmaj.ca/lookup/suppl /doi:10.1503/cmaj.111304/-/DC1). ${ }^{2}$ Chemoprophylaxis should be given to close contacts (Appendix 2, available at www.cmaj.ca/lookup/suppl /doi:10.1503/cmaj.111304/-/DC1).

For references, see Appendix 3, available at www.cmaj.ca/lookup/suppl/doi:10.1503 /cmaj.111304/-/DC1

Competing interests: None declared.

This article has been peer reviewed.

Affiliations: From the Department of Medicine (Moayedi), University of Toronto, and the Division of Infectious Diseases (Gold), University Health Network, Toronto, Ont.

Correspondence to: Dr. Wayne L. Gold, wayne .gold@uhn.on.ca

CMAJ 2012. DOI:10.1503/cmaj.111304 